Howell, M. L. (2008). Decisions with good intentions: Substance use allegations and child protective services screening decisions. Journal of Public Child Welfare, 2(3), 293-316. Published by Taylor \& Francis (ISSN: 15548740). DOI:10.1080/15548730802463546. Record available online at: http://dx.doi.org/10.1080/15548730802463546

\title{
Decisions with Good Intentions: Substance Use Allegations and Child Protective Services Screening Decisions
}

Michael L. Howell

\begin{abstract}
This quantitative study of decision-making factors related to screening maltreatment reports was conducted to investigate whether personal biases, values, and stereotypes surrounding parental drug use and race influenced screening decisions. In one southeastern state, 86 child welfare intake supervisors reviewed 10 scenarios alleging maltreatment. Participants decided which reports to accept for investigation, identified influential decision-making factors, and rated personal and organizational values surrounding parental drug use on a scale developed by the researcher. Participants' decision-making patterns suggest that when their values and child welfare policies conflicted in their desire to protect children, supervisors were willing to compromise policy standards for initiating investigations. The social justice implications of these findings are important for child welfare workers and administrators to consider.
\end{abstract}




\section{INTRODUCTION}

With the destructive force of a tornado, as Califano (1994) described it, substance abuse has torn through families over the past two decades. The damage has only increased over time. While parental drug use is a serious concern, it has also been argued that both investigations and custody decisions are influenced by stereotypes related to substance abuse (Azzi-Lessing \& Olsen, 1996) —stereotypes that may unnecessarily place children in the child welfare system and intrude in families' lives.

Numerous studies have examined the relationship between substance abuse and the investigative process (including Azzi-Lessing \& Olsen, 1996; Besinger et al., 1999; Semidei, Radel, \& Nolan, 2001), including the degree to which substantiation decisions may be influenced by findings of caregiver substance abuse (Sun et al., 2001). Much less research is available on the relationship between substance use and the likelihood that cases will be opened at intake for investigation. It is important to fully understand this relationship as both children and resources are at risk when intake decisions are made. Intake decisions are intended to be based on policy criteria (Besharov, Lowry, Pelton, \& Weber, 1998) and evidence presented in maltreatment allegations. To protect families and scarce agency resources, it is crucial that intake decisions be correct. Thus, it is important to determine whether these decisions are actually influenced by biasing factors leading to incorrect decisions. This study begins to fill this gap by exploring the degree to which a "suspicion" of substance use or abuse influences an intake supervisor to make a determination to investigate a report of abuse or neglect.

\section{LITERATURE REVIEW}

\section{Intake in Child Protective Services (CPS)}

\section{Screening Function}

The "intake" or screening process is the beginning point in addressing a child protective services (CPS) complaint. In most agencies, screening is conducted by caseworkers. Screening involves several stages including receiving the report, exploring the appropriateness of the referral, checking for previous reports, determining the urgency of the response, and assigning the report to an investigator or assessor (Downing, Wells, \& Fluke, 1990; Flick \& Boyette, 1999; Johnson \& Wells, 2000). The most important aspect of the screening process is deciding whether the allegations will be investigated.

\section{Accepting or Rejecting Maltreatment Reports}

Not every report received by a CPS agency is one that should be investigated, and intake workers determine which reports advance further. Historically, CPS hotlines and intake units have been found to screen out approximately 50\% of the reports they receive (Waldfogel, 
1998). Studies have concluded that workers must use their judgment in deciding if allegations reported meet the legal definitions for an incident that can be investigated (Wells, Fluke, \& Brown, 1995). Although policy in most states demands that reports should be accepted based on clear evidence that harm has occurred or is imminent, intake decisions remain open to subjective influences.

\section{Substance Use or Abuse and the Child Welfare System \\ Extent of the Problem}

According to a 2001 survey conducted by the Substance Abuse and Mental Health Services Administration (SAMHSA, 2003), approximately 6 million children lived with at least one parent who met the survey's definition of substance abusing or dependent. In fact, children of substance abusing parents have become the largest group entering the child welfare system (Besinger et al., 1999). An estimated 30\%-80\% of families in CPS caseloads across the nation are alleged to have alcohol or drug-related problems that endanger their children (Shillington, Hohman, \& Jones, 2001; Sun, 2000).

\section{Reliance on Misinformation and Substance Abuse Stereotypes}

Early drug use research from the 1980s shaped substance abuse as both a social problem and child welfare issue. However, the rigor of many early studies has since been challenged along with their findings. Contemporary researchers and treatment providers actually disagree on the harmful physical, emotional, and social effects of drug use (Karanda, 2004). In error, CPS workers may believe that the familiar effects identified in the 1980s and early 1990s-and the persistent stereotypes research from that time created-represent what is actually known about drug use and addiction (Karanda 2004).

CPS workers' knowledge of substance use, abuse, and addiction may be inadequate, leading to reliance on common stereotypes. Karanda (2004) found that CPS workers and supervisors employed negative stereotypical labels (for example, "crackheads" and "drunks") when discussing their clients who engage in drug-related behaviors. She suggests that it is difficult for child welfare workers to "unlearn" what they know about drug use. Munro (1999) argues that even when child welfare workers are presented with evidence that they are wrong, workers resist changing their beliefs and opinions. Thus, workers may continue to rely on, and generalize to clients from, outdated, incorrect, stereotypic information.

\section{Drug Use: Complexity and the Need to Assess Thoroughly}

CPS workers may be insensitive to the complexity that surrounds parental drug use (Sun, 2000). They may believe that parents who use drugs are only concerned about using-a common stereotype. Workers may not consider that some clients feel ambivalent about their 
behavior. Parents may struggle with their behavior and feel guilt over its impact on their children. Sun (2000) interviewed mothers in substance abuse treatment to understand their experiences both with substance abuse and CPS. These mothers reported feeling simultaneously compelled to continue and stop using drugs. The participants desired a normal, "mainstream" (Sun, 2000, p. 144) life and positive relationships with their families and children. Most commonly, they expressed concern that their children have better futures and avoid drug use.

\section{Considering Functional Drug Use: All Drug Use May Not Be Harmful}

Clearly, alcohol and drug use is detrimental in many families, and CPS intervention is justified in situations in which parents' drug-related behaviors compromise children's safety. Yet, in some homes substance use may not lead to maltreatment (McAlpine, Marshall, \& Doran, 2001). Some researchers caution that evidence of a strong empirical relationship between substance use and child maltreatment is still limited in the literature (Hines et al., 2004; Karanda, 2004).

Comprehensive individual assessment remains the key to determining to what degree drugrelated behavior poses a risk to children. However, as Karanda argues, thorough and valid assessment may be impeded by CPS workers' limited understanding of addiction, drug use or abuse, and their reliance on common stereotypes.

\section{Additional Potentially Biasing Factors}

Drug use stereotypes are not the only potential influences on intake decision-making. Other potentially biasing factors have been suggested in the literature. Institutional biases and ideologies (Karanda, 2004), community standards and expectations (Korbin et al., 2000), personal beliefs regarding parental behavior (Smith \& Donovan, 2003), racism (Barth, 2005; Derezotes, Poertner, \& Testa, 2005) and socioeconomic status (Drake \& Zuravin, 1998; Pelton, 1978) may affect decision-making in CPS.

\section{Racism and Behavioral Expectations}

Racism and expectations for behavior may also affect decisions to screen complaints for investigation. Maltreatment reports involving Black children tend to be accepted for investigation more frequently than those involving White children (Gryzlak, Wells, \& Johnson, 2005; Hines et al., 2004). In one screening study, the reports involving Black children had a $90 \%$ acceptance rate for investigation compared to a $68 \%$ rate for White children (Wells et al., 1995). Derezotes and Poertner (2005) reported a similar pattern found in screening decisions in Illinois in 2002. For each maltreatment report accepted involving a White child, three were accepted involving Black children. 
Middle-class White caseworkers, who happen to be the majority of child welfare service providers (Pierce \& Pierce, 1996; Zambrana \& Capellow, 2003), may hold assumptions about the nature of life and behavior in Black and Latino homes and make comparisons to their own experiences and values. Workers of color, although they may share similar racial experiences with their minority clients, may hold very different cultural values than their clients yet make the same comparisons (Lu et al., 2004). McRoy (2002) has suggested that workers of color and their Caucasian peers both internalize the same negative stereotypes about minorities. Workers from both groups may similarly have internalized stereotypes about drug use behaviors in different racial groups.

\section{Socioeconomic Status}

Drake and Zuravin (1998), advancing Pelton's (1978) "Myth of Classlessness," proposed that due to a visibility bias, low income families - who regularly interact with mandated reporters in public agencies-are frequently reported and investigated. Poor minority families are clearly more vulnerable to being investigated. Because crime and drug use reputations are often associated with lower socioeconomic and less influential geographical areas within a community, where a family lives may determine whether the family will be investigated (Chibnal et al., 2003). Agencies may be biased towards accepting reports from particular racial, ethnic, and socioeconomic communities within their jurisdictions, even when similar allegations received from other communities might not receive the same agency response.

\section{PURPOSE OF THE STUDY}

The major purpose of this study is to evaluate whether the presence of substance use or abuse allegations influence the acceptance of reports that, otherwise, would not meet the legal and policy criteria established to initiate an investigation. Additional factors in the decision to accept cases for investigation, such as alleged victim race and worker education, will also be examined. Several hypotheses grounded in the existing literature emerged:

1. Hypothesis 1: The number of scenarios accepted for investigation will positively correlate with respondents' feelings regarding caregiver substance use or abuse. Respondents who possess more negative feelings about substance abuse, as evidenced by higher scores on a values scale, will accept more scenarios for investigation.

2. Hypothesis 2: Decision factors related to substance use (Drugs Present in the Home, Drug Use of Caregiver, and Alcohol Use of Caregiver) will positively correlate with respondents' feelings regarding caregiver substance use or abuse. Respondents with higher values scales scores will more consistently choose these decision factors. 
3. Hypothesis 3: The race of the alleged victim will influence the decision to accept a report for investigation. Scenarios involving Caucasian children will be accepted for investigation less frequently than when non-Caucasian children are identified in scenarios.

Three additional research questions, not addressed in the existing literature, emerged related to the influence of training and education:

1. Does completing intake training influence acceptance rates?

2. Does a social work education influence respondents' acceptance rate?

3. Does a social work education influence respondents' values scale score?

\section{METHODOLOGY}

Child welfare staff assigned the responsibility of screening child maltreatment reports in their individual counties were surveyed by mail to assess their decision-making practices. In addition to providing basic demographic information (i.e., gender, race, education, years of child welfare experience, and years as an intake supervisor) respondents completed a survey instrument constructed by the researcher that included vignettes describing child maltreatment situations.

\section{Sample}

The study population involved in this research consisted of county Department of Social Services staff assigned the responsibility of screening child maltreatment reports in their individual counties in one southeastern state. In that state, each county is required to assign this responsibility to a primary staff member, predominantly a supervisor or manager; thus the study population included a minimum of 100 potential study participants. When the primary decisionmaker is unavailable, screening decisions are made by other staff. To consider participants' responses as representative of the maltreatment screening decisions normally made in their counties, the researcher chose to target the staff members who were responsible for screening at least $75 \%$ of the reports received by their department. Although state policy requires a twoparty decision for rejecting a maltreatment report (involving the intake worker who recorded the report and the staff member responsible for supervising intake services or another administrator), the researcher decided to limit the study to the supervisory staff members as it seemed likely that their decisions would ultimately overrule the opinions of subordinate staff if they conflicted.

A listing of supervisory staff assigned primary responsibility for screening child maltreatment reports was constructed by contacting each county and asking for contact information regarding 
the staff member in this position. The potential participants were then sent an introductory letter explaining the research project and encouraging their participation. A follow up letter reminding them that a research instrument would be mailed to them was sent some weeks later.

Approximately 2 weeks after the research materials were mailed, an e-mail reminder was sent to all sample members to further encourage participation.

\section{Measures}

\section{Instrument Construction}

In an effort to develop case vignettes that realistically represented allegations that were likely to be reported to CPS, but would not meet legal or policy criteria for investigation, the researcher reviewed screened out (rejected) reports in a large urban Department of Social Services in a southeastern state. All of the rejected reports selected included drug or alcohol allegations (including, but not limited to, specific or vague alcohol or drug use behavior, and/or presence of drug paraphernalia) in 2001 between January and September. Rejected reports for other forms of maltreatment were also sampled. The reports reviewed were all rejected because they did not meet the legal criteria necessary for initiating a CPS investigation in a state that had not, at that time, adopted a dual-response process, meaning allegations could only be investigated; no voluntary services could be offered for less serious concerns. Based on maltreatment allegations that had been reported during that time frame, 22 initial vignettes were constructed. In addition to demographic information (age, gender, ethnicity/race of children and caregivers), the scenarios included alcohol and/or drug use allegations that were intentionally vague.

Experienced CPS staff members were then identified within the agency from which the intake data were obtained to provide consultation regarding content validity and construction of the research instrument. Seven professionals participated in the process (five child welfare supervisors from CPS who were at times responsible for screening reports in the absence of the designated intake supervisor, one program manager responsible for a child welfare division, and the agency's trainer who had trained the state's intake screening decision-making course).

This survey design group was asked to review the scenarios then rate them regarding their realism on a scale of 1 (highly unrealistic) to 4 (highly realistic) and the likelihood of workers encountering similar situations in the field. Using the group's feedback, 10 scenarios were chosen that appeared to best represent the broad range of problems encountered by CPS workers. Once the 10 scenarios were identified, two of the supervisors, both with extensive experience, were provided a copy of each scenario along with an extensive list of potential factors that might influence decision-making, generated from the literature review. The supervisors were asked to identify each factor that was believed to be relevant to decisionmaking in each situation, assuming the case was accepted for investigation. A wide range of potentially applicable and non-applicable factors was provided for each scenario. The vignettes did include adequate relevant information to make a screening decision. Feedback regarding the meaning or relevance of particular factors was used in determining the final list of 30 potential decision factors included in the survey instrument. 
The survey design group was also asked a series of open-ended questions regarding their general decision-making practices, particular practices in reports involving alcohol and substance use allegations, and their interpretation of State child welfare policy regarding screening and justification for State intervention. Their answers were used to develop a brief scale to assess values related to decision-making in reports involving substance use allegations.

They were later administered the draft instrument to determine how much time was required to complete the survey and to seek feedback regarding unclear directions or test items, as well as to reassess the instrument's face validity. In response to comments, questions specifically involving alcohol were removed as participants expressed concern that social considerations regarding alcohol use are often significantly different from those related to the use of other drugs and could influence responses.

\section{Decision-Making Practices}

In addition to providing demographic data, respondents completed a survey instrument constructed by the researcher. The instrument included 10 vignettes describing child maltreatment allegations and demographics related to the alleged victims, caregivers, and reporters. The scenarios were based on similar allegations that had been determined to not meet legal or policy criteria for investigation in actual child maltreatment reports. Participants were asked to review each scenario and first decide whether or not to accept the situation for investigation. They were then asked to determine which type(s) of maltreatment (abuse, neglect, or both) the scenario represented if it was accepted; whether it reflected low, moderate, or high risk to the child(ren) involved; and whether or not an emergency response would be required. Each scenario was accompanied by the same set of 30 potential factors that might influence the decision being made. Respondents were asked to identify the specific factors that affected their decisions in the scenarios that they chose to accept for investigation. Two scenarios were included that paralleled allegations included in two others; in these two particular scenarios, the descriptions of the family's circumstances were slightly altered but the reported concerns were the same with only the exclusion of substance use allegations.

\section{Values Toward Caregiver Substance Use}

Respondents also completed a seven-item scale constructed by the researcher for this study to assess values related to caregiver substance use and decision-making. The values scale measures, on a 4-point Likert scale, the degree to which respondents agree with the statements provided in the seven test items: 
Strongly Disagree, Disagree, Agree, Strongly Agree:

1. I believe allegations of drug use by caregivers should always be investigated.

2. I believe state statutes require all allegations of drug use by caregivers to be investigated.

3. I believe drug use by caregivers is wrong.

4. In my county, if drug use by caregivers is found during an investigation, then the investigation will be substantiated.

5. I believe my decisions regarding intake reports are consistent with those of other intake supervisors.

Never, In Some Instances, In Most Instances, In All Instances:

1. I believe drug use by caregivers leads to maltreatment of their children.

2. In my county, allegations of drug use by caregivers are investigated ...

Higher scores are believed to indicate a greater degree of value-influenced decision-making versus objective, or evidence-influenced, decision-making.

\section{Data Collection Procedures}

A total of 100 survey packets were mailed to the identified intake supervisors. The packet included a brief summary of the nature of the research project, instructions for completing and returning the survey instrument, and a statement reassuring participants that responses would be kept confidential. In addition to the survey instrument, a postage paid return envelope was included for participants' convenience in returning the materials. In accordance with research policy requirements of the child welfare department in which the researcher was employed at the time data were collected, informed consent was acknowledged by the participants through the act of returning the completed confidential questionnaires. The methodological process, including sampling, consent procedures and participant protection, was further reviewed and affirmed by the institutional review board of the author's academic institution prior to beginning data analysis. The response rate for receiving completed survey instruments was $86 \%$.

\section{Data Analyses}

Data analyses were conducted using SPSS 12.0 (SPSS, Inc., Chicago, Illinois). Data were described and analyzed using univariate and bivariate statistical methods. To determine the strength of the relationships found among variables, Pearson's $r$ correlation coefficients were 
estimated. To explore differences in means between respondent groups that emerged from the data, $t$-tests and One-way analysis of variance (ANOVA) were employed when variable measurement would allow these procedures.

\section{RESULTS}

\section{Demographics}

The sample comprised 86 respondents who completed and returned the survey instrument in April 2002. The sample included 11 men (12.8\%) and 74 women (86\%) with one participant's gender unidentified. Race/ethnicity was primarily White, with 68 (79\%) White respondents and $17(19.8 \%)$ Black or Latino respondents. Given the small number of Hispanic participants, the non-White race/ethnicity categories were collapsed to protect those participants' identities. All respondents reported completing college degrees. Of the 12 respondents who had earned masters degrees, three (3.5\%) were in social work. Table 1summarizes the respondents' educational background. A total of 72 respondents (84\%) worked in rural counties. The participants were primarily supervisory level staff responsible for supervising intake workers, 75 (87\%) of whom reported meeting the criteria for screening $75 \%$ of the child maltreatment reports received in their counties.

TABLE 1. Degree Type and Major Fields

\begin{tabular}{lrr}
\hline Highest Degree Type and Field & $n$ & \multicolumn{1}{c}{$\%$} \\
\hline Undergraduate & & \\
$\quad$ Social Work & 17 & 19.77 \\
Other Undergraduate & 17 & 19.77 \\
Sociology & 16 & 18.61 \\
Psychology & 10 & 11.64 \\
Business & 8 & 9.30 \\
$\quad$ Nursing & 4 & 4.65 \\
Graduate & & \\
$\quad$ Counseling & 5 & 5.81 \\
Social Work & 3 & 3.49 \\
Public Health & 2 & 2.32 \\
Public Administration & 1 & 1.16 \\
$\quad$ Nursing & 1 & 1.16 \\
Missing & 2 & 2.32 \\
Total $(N)$ & 86 & 100.00 \\
\hline
\end{tabular}


One participant reported less than 6 months experience screening maltreatment reports, and two reported being responsible for screening reports for more than 20 years, with the mean amount of time participants had screened reports being 5.45 years ( $S D=1.6$ years). The participants' mean score for years of experience in child welfare prior to becoming responsible for screening reports was 6.24 years ( $S D=1.5$ years). Twenty-five participants $(29 \%)$ reported that they did not have child welfare experience before beginning their intake supervision positions, but of the remaining 61 participants (71\%), all but $9(10 \%)$ reported having more than 3 years child welfare experience prior to becoming responsible for screening child maltreatment reports, suggesting the sample was composed of experienced supervisors. Only $43 \%$ of the participants $(n=37)$ reported completing the state's mandatory training course for intake screening decision-making at the time data were collected.

\section{Instrument Reliability and Validity}

The researcher developed the instrument employed in this study and caution should be observed, as in the case of any newly developed instrument, in accepting that its purported measurement properties are truly reliable and valid. It is acknowledged that rigorous testing is required to confidently warrant these qualities. However, preliminary exploration of the instrument's strength and sensitivity through the use of a test group and additional efforts were encouraging.

\section{Case Scenarios}

The vignettes and their rate of acceptance for investigation are found in Table 2. As described previously, extensive efforts were made to develop realistic scenarios that included believable, commonly encountered maltreatment allegations. A group of CPS professionals with intake experience determined the scenarios to be realistic and reflective of practice. Their feedback suggested the instrument possessed, at minimum, face and content validity. These professionals also helped cull out irrelevant decision-factors from the final list presented in the instrument. According to Finch (1987), who has written extensively on vignette methodology, scenarios that are believable and realistic can be considered as possessing strong validity, particularly when they are constructed using language familiar to the participant population and represent the complexity and ambiguity found in the practice environment. The scenarios in the instrument also conform to guidelines for vignette development provided by Payne and Bettman (1992). They suggest that in decision-making studies information must be conveyed in a format familiar to the participants, using commonly encountered descriptive language to minimize procedural and descriptive variance. The scenarios included in the instrument were realistic and presented information in a familiar CPS report format, written in a style that mimicked actual maltreatment reports that intake supervisors would review in daily practice. 
TABLE 2. Vignettes, Victim Race and Rates of Acceptance

\begin{tabular}{|c|c|c|c|c|}
\hline \multirow[b]{2}{*}{ Scenario } & \multirow[b]{2}{*}{ Abbreviated Allegations } & \multirow{2}{*}{$\begin{array}{l}\text { Victim } \\
\text { Race }\end{array}$} & \multicolumn{2}{|c|}{ Accepted } \\
\hline & & & (n) & $(\%)$ \\
\hline 1 & $\begin{array}{l}\text { Drugs used and sold in residence; neighbors feed } \\
\text { and clothe children }\end{array}$ & Black & 1 & 1.2 \\
\hline 2 & $\begin{array}{l}\text { Child has missed more than } 5 \text { days of school; } \\
\text { clothes are dirty and too big; reporter suspects drug } \\
\text { use }\end{array}$ & White & 3 & 3.5 \\
\hline 3 & $\begin{array}{l}\text { Mother and roommate use drugs; roommate } \\
\text { prostitutes; reporter suspects children are not cared } \\
\text { for }\end{array}$ & White & 9 & 10.5 \\
\hline 4 & $\begin{array}{l}\text { Family stayed in homeless shelter until evicted due } \\
\text { to mother being intoxicated; mother arrested for } \\
\text { being disruptive; child placed in teen shelter }\end{array}$ & Black & 6 & 7.0 \\
\hline 5 & $\begin{array}{l}\text { Child frequently "reeks" of marijuana when arrives } \\
\text { at daycare; mother has same smell; child appeared } \\
\text { nauseous, sleepy, and uncoordinated today }\end{array}$ & White & 11 & 12.8 \\
\hline 6 & $\begin{array}{l}\text { The house is filthy and has roaches; mother and } \\
\text { uncle smoke marijuana; there is scarcely any food; } \\
\text { reporter describes the mother as "unfit" }\end{array}$ & Black & 19 & 22.0 \\
\hline 7 & $\begin{array}{l}\text { Father left child with grandmother; child can remain } \\
\text { with her; no contact from parents; reporter believes } \\
\text { parents use alcohol but leave child with other } \\
\text { caregivers; reporter believes child is dirty and "not } \\
\text { cared for" }\end{array}$ & Black & 11 & 12.8 \\
\hline 8 & $\begin{array}{l}\text { The mother and live-in boyfriend are selling drugs } \\
\text { from the home }\end{array}$ & Hispanic & 18 & 20.9 \\
\hline 9 & $\begin{array}{l}\text { Reporter believes the parents are "unfit;", they live in } \\
\text { a house that is roach-infested and "filthy;" there is } \\
\text { not much food in the house }\end{array}$ & Black & 6 & 7.0 \\
\hline 10 & $\begin{array}{l}\text { Child has missed } 12 \text { days of school and is frequently } \\
\text { tardy; mother is unresponsive; child is generally dirty } \\
\text { and wears same oversized clothes repeatedly }\end{array}$ & White & 2 & 2.3 \\
\hline
\end{tabular}

Note: The complete instrument, including the specific decision factors, is available by request.

\section{Values Scale}

The values scale had an acceptable level of reliability (Cronbach's alpha $=.76$ ), suggesting the internal consistency among items is fairly strong and the scale adequately measured the values of sample participants as intended. It appears to demonstrate an acceptable degree of construct validity as well. If the scale is sensitive to bias and performs as expected, participants' summated scores should be higher when a greater number of scenarios are accepted. In this sample it did perform as expected, yielding higher values scale scores for those participants who accepted more scenarios to investigate. 


\section{Hypotheses and Research Questions}

The sample varied in accepting reports for investigation. As Table 2 indicates, every scenario was accepted by at least one respondent and some had acceptance rates as high as $22 \%$. Returning to the first hypothesis, the number of scenarios accepted for investigation and the respondents' values scale scores were significantly correlated $(r=.41, p<.01)$. Respondents with higher values scale scores accepted more scenarios for investigation than those participants with lower scores. The data were collapsed into three groups due to the limited number of cases. Group one accepted 0-3 scenarios, group two accepted 4-6 scenarios, and group 3 accepted 7-10 scenarios. As the analysis of variance (ANOVA) in Table 3 suggests, when the groups were compared on the number of scenarios accepted for investigation, the main effect of the values scale score was significant, $F(2,83)=6.245, p=.003$. Chi-square tests were employed to investigate any potential significant differences in members of the groups and to confirm that the groups were roughly equivalent. The tests performed included group and race, group and gender, and group and education. There were no significant differences between members of the three groups that might have influenced the relationship between number of scenarios accepted and values scale score.

TABLE 3. Analysis of Variance for Values Scale Score by Scenario Acceptance Groups

\begin{tabular}{lrcc}
\hline Source & $d f$ & Mean Square & $F$ \\
\hline Between Groups & 2 & 1327.949 & $6.245^{*}$ \\
Within Groups & 83 & 212.636 & \\
\hline
\end{tabular}

Note: Number of scenarios accepted by group: Group $1(0-3)$, Group 2 (4-6), Group 3 (7-10).

$" p=.003$.

Table 4 addresses the second hypothesis by examining the identification of the factors Drugs Present in the Home, Drug Use of Caregiver, and Alcohol Use of Caregiver as influencing decision making within the groups of respondents who accepted particular scenarios for investigation. Of the respondents who chose to investigate a given scenario, this is the percentage of the group who also identified one or more of these particular factors. In the sample, respondents with higher values scale scores were more likely to identify drug use (as evidenced by selecting one or more of the factors related to drugs or alcohol) as influencing the decision to investigate. Of 86 respondents 77 (90\%) identified substance use as a decisionmaking factor in at least one scenario. Further, as demonstrated in Table 5, values scale scores differed between the respondents who never identified drugs use as influencing their decisions across the 10 scenarios and the group of respondents who did identify it at least once. The values scale scores differed between these two groups of respondents more than would have been expected by chance, $t(84)=2.038, p=.045$. 
Given that the literature has frequently found race to be a variable that influences decision making in CPS, the predicted outcome for the third hypothesis was that a similar relationship between race and the decision to accept scenarios involving children of color for investigation would be found in this sample. Indeed, the predicted relationship appeared in the data. As Table 6 suggests, scenarios that involved White children were selected for investigation at a lower rate than those that involved Black and Latino children, $t(81)=8.114, p<.001$. Interestingly, the results showed there was no difference between the scenarios accepted for investigation by White respondents and those accepted by Black and Latino respondents, $t(82)=-.488, p=$ .627 . Respondents' race did not seem to influence acceptance rates in the sample.

TABLE 4. Key Substance Factors That Influenced Decision to Accept

\begin{tabular}{cccc}
\hline Scenario & $\begin{array}{c}\text { Drugs Present } \\
\text { In Home } \\
(\%)\end{array}$ & $\begin{array}{c}\text { Drug Use } \\
\text { of Caregiver } \\
(\%)\end{array}$ & $\begin{array}{c}\text { Alcohol Use } \\
\text { of Caregiver } \\
(\%)\end{array}$ \\
\hline 1 & 80.2 & 79.1 & 1.2 \\
2 & 20.9 & 37.2 & \\
3 & 57.0 & 70.9 & \\
4 & 1.2 & 2.3 & 48.8 \\
5 & 38.4 & 48.8 & 1.2 \\
6 & 55.8 & 73.3 & \\
7 & 1.2 & 2.3 & 8.1 \\
8 & 18.6 & 7.0 & \\
9 & & & \\
10 & & & \\
\hline
\end{tabular}

TABLE 5. Mean Values Scale Score by Identification of Drugs as a Factor to Accept

\begin{tabular}{lrc}
\hline \multirow{2}{*}{ Drugs are Factor } & \multicolumn{2}{c}{ Values Scale } \\
\cline { 2 - 3 } & $n$ & $M(S D)$ \\
\hline Yes & 77 & $44.23(15.36)^{*}$ \\
No & 9 & $33.33(13.32)$ \\
\hline
\end{tabular}

Note: Score indicates the mean values scale score for group identifying "Drugs are Factor" in at least one accepted scenario and group that did not identify that factor in any accepted scenario.

${ }^{*} t(84)=2.04, p=.04$. 
The first research question was related to the influence of completing specialized intake training offered to intake supervisors. Only 37 of the 84 respondents who answered the question had completed the state's mandatory intake training course at the time data were collected. The required 16-hour standardized curriculum reviewed child welfare policy, including standards for determining that allegations met the definitions for child maltreatment. Participants were presented with exemplar allegations then guided through interpreting policy to determine whether or not the allegations should be accepted for investigation or screened out. The group of intake supervisors who had completed intake training and the group who had not chose a comparable mean number of scenarios to be investigated (6.2 and 5.7 respectively). No association was found between completing the intake training course and the number of scenarios accepted, $t(83)=.77, p=.446$.

TABLE 6. Scenario Mean Acceptance Rate Based on Child's Race

\begin{tabular}{lcr}
\hline & \multicolumn{2}{c}{ Mean Number } \\
\cline { 2 - 3 } Child's Race & Accepted & $S D$ \\
\hline Caucasian & $2.4^{*}$ & 1.26 \\
Non-Caucasian & 3.6 & 1.20 \\
\hline
\end{tabular}

${ }^{*} t(81)=8.11, p<.001$.

TABLE 7. Mean Acceptance Rate and Values Scale Score by Social Work Background

\begin{tabular}{lccc}
\hline $\begin{array}{l}\text { Social Work } \\
\text { Degree }\end{array}$ & $\mathrm{n}$ & $\begin{array}{c}\text { Mean Number } \\
\text { Accepted (SD) }\end{array}$ & $\begin{array}{c}\text { Mean Values } \\
\text { Scale Score }(S D)\end{array}$ \\
\hline Yes & 21 & $5.95^{\star}(2.01)$ & $47.35^{\star *}(18.89)$ \\
No & 65 & $6.11(2.08)$ & $41.71(14.07)$ \\
\hline
\end{tabular}

${ }^{*} t(84)=-.30, p=.76 ; " ' t(84)=1.46, p=.15$.

In order to examine the last two research questions, graduate and undergraduate degrees were combined to analyze the possible relationship between social work education and both acceptance rates and respondents' values scale scores. In this sample, educational differences appeared to have little influence on decision-making. Participants educated as social workers made similar decisions to their counterparts educated in different fields. As reflected in Table 7, for respondents, having been educated as a social worker had little influence on either the acceptance rate, $t(84)=-.300, p=.765$, or Values Scale scores, $t(84)=1.465, p=.147$. 


\section{DISCUSSION}

This study contributes to the growing body of child welfare decision-making literature. The results are particularly important as they emphasize the apparent significance of worker bias, or at least strongly held beliefs or stereotypes, regarding substance use and race in intake decision-making. The findings of this study echo Azzi-Lessing and Olsen (1996), Karanda (2004), and others who have suggested workers' substance user stereotypes may influence CPS practice. Further, the findings in this study support other studies' findings (Derezotes \& Poertner, 2005; Gryzlak et al., 2005; Wells et al., 1995), which have identified race as a key variable in child welfare decision-making.

\section{Entrenched Racial and Drug Use Beliefs}

Some child welfare scholars suggest that workers, in general, demonstrate an erroneous tendency to seek to confirm their assumptions and ignore evidence that disconfirms those beliefs (MacDonald, 2001; Munro, 1999). It follows, then, that workers' assumptions about substance use and abuse along with racial and drug use stereotypes might become entrenched over time and be resistant to change. It is easier to understand the idea that workers may have entrenched beliefs regarding race and substance use that might affect practice when cognitive dissonance theory is considered as a way of partially explaining it.

Cognitive dissonance theory (Festinger, 1989) offers one possible explanation for allowing personal beliefs to influence practice consciously or unconsciously. According to this social psychology theory, humans develop and maintain cognitions (ideas, beliefs, values, stereotypes, and assumed "facts") and prefer that their cognitions be consonant, or complement each other. They also prefer that their cognitions and behaviors be complementary (Festinger, 1989; Harmon-Jones \& Mills, 1999). When faced with information that conflicts with existing cognitions, or when a particular behavior would counter cognitions, people experience dissonance, or tension. In order to avoid or reduce this tension, people adopt a response strategy: 1) choose to act in ways most consistent with their existing cognitions, 2) ignore contradictory information, or, in some cases, 3) do actually modify or replace existing cognitions (Festinger, 1989; Harmon-Jones \& Mills, 1999).

\section{Limitations}

Some limitations of the study should be acknowledged before proceeding to discuss practice implications and future research. Decision-making is a complex process and may likely be subject to variation influenced by many factors within the decision-maker's daily high-demand environments. Decision choices might be consistent across multiple test administrations but might as easily be likely to change under different environmental demands. Respondents were forced to make decisions based on limited (but adequate) contextual information and evidence. It is generally acknowledged, however, that decision makers employ a limited amount of information, even when more detail is available, to make decisions (Kahneman, Slovic, \& 
Tversky, 1982). Finally, although the validity and reliability of the test instrument with this sample are encouraging, they cannot be assumed absent further testing.

Generalizability of the findings must be considered with caution. Although the sample is relatively homogenous in terms of demographics (predominantly White, female, and practicing in rural localities), the make up of the sample did realistically represent the diversity found in the state's intake decision-makers at that time. Thus the findings would seem to be generalizable to the population of decision-makers from which the sample was drawn, but not to other intake decision-makers in other settings. Certainly the findings would likely be different had the data been collected from a larger sample that included a more diverse group of participants drawn from multiple states, rural and urban practice settings, guided by different child welfare policies. The intake decision-maker populations in other states might demonstrate considerable demographic, practice experience, and educational variability, all factors that could influence findings.

\section{Implications for Practice}

The findings suggest that intake training focusing solely on policy and its interpretation may be inadequate. Complementary training specifically emphasizing the complex nature of decisionmaking is suggested to encourage awareness of the process employed when making intake decisions. In this training, it is also important to emphasize consciously considering factors such as race and personal biases related to drug use that have been found to influence decisions. Thorough substance use, abuse and addiction education, which addresses drug use stereotypes, is also recommended to help intake supervisors understand differences in drugrelated behavior and how these differences influence risk. This type of training may prepare intake supervisors to distinguish functional substance use from substance abuse.

The findings also suggest that details may make a difference in the decision. Intake workers should be encouraged to capture as much relevant detail as possible when accepting a maltreatment referral from a reporter. The alleged effects of the caregivers' drug use on children's care are particularly important to document in order to increase the likelihood of the intake supervisor making an evidence-based decision supported by policy. Equally as important, it is crucial to gather all pertinent data regarding children's care to avoid screening out serious maltreatment reports that should be accepted. If an intake report is not documented thoroughly, a vulnerable child may be left at risk of experiencing severe abuse or neglect.

\section{Implications for Research}

The study leads to several avenues for additional research. Little research has been conducted that focuses on the intake segment of the child welfare continuum and requisite knowledge and skills for performing this crucial function. The intake decision-making process remains poorly understood. It is important to continue to explore and articulate this decision-making process. In a future study it might be productive to randomly assign particular conditions (such as race or 
drug use allegations) across standard scenarios in a similar series of administrations. Other studies might attempt to determine which of the identified decision factors, when combined in a model, predict decisions. Continued exploration of intake supervisors' knowledge of substance use and abuse and the validity of their perceptions regarding drug using caregivers is suggested. Further exploration of the role of intake supervisors' personal values in decisionmaking should also be considered.

CPS intake decision-making is a complex process that involves considerable risk even when maltreatment reports include detailed information. Intake supervisors likely feel the tension between protecting children by screening reports in and judiciously conserving resources by rejecting some. It is likely that intake supervisors accept reports with good intentions, based on their desire to protect children. However, in some situations, when good intentions are the result of worker biases related to drug use or race, families may actually be harmed through their exposure to the child welfare system when CPS intrusion is unwarranted. Consider again the mounting evidence suggesting CPS responds to Black children differently, with these children being particularly likely to be separated from their families, often removed from their homes only to linger in the foster care system (Barth, 2005; Derezotes \& Poertner, 2005; McRoy, 2002). Other families may be harmed-and other children severely maltreated-when CPS workers' attention and energy is misdirected on families experiencing minimal risk or who do not really need their assistance. In order to protect children who actually need to be protected, it is crucial that intake supervisors and other child welfare administrators understand how decision-making can be influenced by personal and institutional biases and take steps to eliminate that influence.

\section{NOTES}

Acknowledgements: This study was supported by the Guilford County Department of Social Services. I would like to gratefully acknowledge the support of the administration, the Child Protective Services supervisors, and the intake unit. For their mentoring and constructive feedback, I am indebted to Robert Wineburg and Kenneth Gruber, University of North Carolina at Greensboro, and to Marilyn Biggerstaff, Pat Dattalo, Ann Nichols-Casebolt, and, particularly, Humberto Fabelo, Virginia Commonwealth University. Appreciation is also expressed to the anonymous reviewers for their insights and feedback. This article developed from a presentation made at the annual conference of the Society for Social Work Research, January 14, 2005.

$* p=.003$.

*t $(84)=2.04, p=.04$.

$* t(81)=8.11, \mathrm{p}<.001$

*t $(84)=-.30, p=.76$;

$* * t(84)=1.46, \mathrm{p}=.15$. 


\section{REFERENCES}

Azzi-Lessing, L., \& Olsen, L. J. (1996). Substance abuse-affected families in the child welfare system: New challenges, new alliances. Social Work, 41, 15-23.

Barth, R. P. (2005). Child welfare and race: Models of disproportionality. In D. M. Derezotes, J. Poertner, \& M. F. Testa (Eds.), Race matters in child welfare: The overrepresentation of African American children in the system (pp. 25-46).

Washington, DC: Child Welfare League of America, Inc.

Besharov, D. J., Lowry, M. R., Pelton, L. H., \& Weber, M. W. (1998). Four commentaries: How we can better protect children from abuse and neglect. The Future of Children, 8, 120-132.

Besinger, B. A., Garland, A. F., Litrownik, A. J., \& Landsverk, J. A. (1999). Caregiver substance abuse among maltreated children placed in out-of-home care. Child Welfare, 78, 221-239.

Califano, J. A. (1994). The least among us children of substance-abusing parents [sic]. America, 180, 10-12.

Chibnal, S., Dutch, N. M., Jones-Harden, B., Brown, A., Gourdine, R., Smith, J., et al. (2003). Children of color in the child welfare system: Perspectives from the child welfare community. Washington, DC: United States Department of Health and Human Services Children's Bureau, Administration for Children and Families.

Derezotes, D. M., \& Poertner, J. (2005). Factors contributing to the overrepresentation of African American children in the child welfare system. In D. M. Derezotes, J. Poertner, \& M. Testa (Eds.) Race matters in child welfare: The overrepresentation of African American children in the system (pp. 1-23). Washington, DC: CWLA Press.

Derezotes, D. M., Poertner, J., \& Testa, M. F. (2005). Introduction. Race matters: The overrepresentation of African American children in the system. Washington, DC: Child Welfare League of America, Inc.

Downing, J. D., Wells, S. J., \& Fluke, J. (1990). Gatekeeping in child protective services: A survey of screening policies. Child Welfare, 69, 357-369.

Drake, B., \& Zuravin, S. (1998). Bias in child maltreatment reporting: Revisiting the myth of classlessness. American Journal of Othopsychiatry, 68, 295-304.

Festinger, L. (1989). A theory of cognitive dissonance. In S. Schacter, \& M. Gazziniga (Eds.) Extending psychological frontiers: Selected works of Leon Festinger (pp. 201-237). New York: The Russell Sage Foundation.

Finch, J. (1987). Research note: The vignette technique in survey research. Sociology, 21(1), 105-114. 
Flick, J., \& Boyette, S. (1999). Intake in child welfare services. Chapel Hill, NC: Jordan Institute for Families.

Gryzlak, B. M., Wells, S. J., \& Johnson, M. A. (2005). The role of race in child protective services screening decisions. In D.M. Derezotes, J. Poertner, \& M. Testa (Eds.) Race matters in child welfare: The overrepresentation of African American children in the system (pp. 63-96). Washington, DC: CWLA Press.

Harmon-Jones, E., \& Mills, J. (1999). An introduction to cognitive dissonance theory and an overview of current perspectives on the theory. In E. Harmon-Jones \& J. Mills (Eds.) Cognitive dissonance: Progress on a pivotal theory in social psychology (pp. 3-21). Washington, DC: American Psychological Association.

Hines, A. M., Lemon, K., Wyatt, P., \& Merdinger, J. (2004). Factors related to the disproportionate involvement of children of color in the child welfare system: A review and emerging themes. Children and Youth Services Review, 26, 507-527.

Johnson, M. A., \& Wells, S. J. (2000). Screening in child protective services: A literature review. Urbana-Champaign, IL: University of Illinois at UrbanaChampaign, School of Social Work.

Jordan Institute for Families. (1999, September). Substance abuse and child welfare. Children's Services Practice Notes [On-line serial], 4(4). Retrieved June 26, 2001, from http://www.ssw.unc.edu/fcrp/cspn/vol4_no4.htm

Kahneman, D., Slovic, P., \& Tversky, A. (1982). Judgments under uncertainty: Heuristics and biases. Cambridge, England: Cambridge University Press.

Karanda, K. E. (2004). A constructivist inquiry on the meaning of substance abuse for child protective services (Doctoral dissertation, Virginia Commonwealth University, 2004). Dissertation Abstracts International, UMI3166854.

Korbin, J. E., Coulton, C. J., Lindstrom-Ufuti, H., \& Spilsbury, J. (2000). Neighborhood views on the definition and etiology of child maltreatment. Child Abuse \& Neglect, 24, 1509-1527.

Lu, Y. E., Landsverk, J., Ellis-Macleod, E., Newton, R., Ganger, W., \& Johnson, I. (2004). Race, ethnicity, and case outcomes in child protective services. Children and Youth Services Review, 26(5), 447-461.

MacDonald, G. (2001). Effective interventions for child abuse and neglect: An evidence-based approach to planning and evaluating interventions. Chichester, England: John Wiley \& Sons, Ltd.

McAlpine, C., Marshall, C. C., \& Doran, N. H. (2001). Combining child welfare and substance abuse services: A blended model of intervention. Child Welfare, 80, 129-149. 
McRoy, R. (2002, April 29). Color of child welfare policy: Racial disparities in child welfare services. Hunter College School of SocialWork ChildWelfare Lecture Series. Retrieved August 8, 2005, from www.childwelfare.gov/systemwide/cultural/ disporp/related.cfm

Munro, E. (1999). Common errors of reasoning in child protection work. Child Abuse and Neglect, 23, 745-758.

Payne, J. W., \& Bettman, J. R. (1992). Behavioral decision research: A constructivist processing perspective. In M. R. Rosenzweig \& L.W. Porter (Eds.), Annual review of psychology (Vol. 43, 87-131). Palo Alto, CA: Annual Reviews, Inc.

Pelton, L. (1978). Child abuse and neglect: The myth of classlessness. American Journal of Orthopsychiatry, 48, 608-617.

Pierce, R. L., \& Pierce, L. H. (1996). Moving towards cultural competence in the child welfare system. Children and Youth Services Review, 18(8), 713-731.

Semidei, J., Radel, L. F., \& Nolan, C. (2001). Substance abuse and child welfare: Clear linkages and promising responses. Child Welfare, 80, 109-128.

Shillington, A. M., Hohman, M., \& Jones, L. (2001). Women in substance use treatment: Are those also involved in the child welfare system different? Journal of Social Work Practice in the Addictions, 1(4), 25-46.

Smith, B. D., \& Donovan, S. E. F. (2003). Child welfare practice in an organizational and institutional context. Social Service Review, 77(4), 541-556.

Substance Abuse and Mental Health Services Administration (SAMHSA). (2003). Children living with substance-abusing or substance-dependent parents. The NHSDA Report. Retrieved March 1, 2007, from http://www.oas.samhsa.gov/2K3/ children/children.pdf

Sun, A. (2000). Helping substance-abusing mothers in the child-welfare system: Turning crisis into opportunity. Families in Society: The Journal of Contemporary Human Services, 81(2), 142-151.

Sun, A., Shillington, A. M., Hohman, M., \& Jones, L. (2001). Caregiver AOD use, case substantiation, and AOD treatment: Studies based on two southwestern counties. Child Welfare, 80(2), 151-177.

Waldfogel, J. (1998). Rethinking the paradigm for child protection. The Future of Children, 8, 104-119.

Wells, S. J., Fluke, J. D., \& Brown, C. H. (1995). The decision to investigate: Child protection practice in 12 local agencies. Children and Youth Services Review, 17(4), 523-546.

Zambrana, R. E., \& Capellow, D. (2003). Promoting Latino child and family welfare: Strategies for strengthening the child welfare system. Children and Youth Services Review, 25(10), 755-780. 